\title{
Analysis of Learners' Interactive Behaviours in Online Forum
}

\author{
Dan Xia, Huirong Ke, Yuan Tian, Qiusha Min, and Zhifeng Wang
}

\begin{abstract}
This study analyzed the interactive behaviours among students in online course forum. The subject of this study was 30 students who participated in a course. The course was delivered in a mixed mode which contained online mode and face-to-face mode. The whole semester was divided into three six-week periods which represented the earlier stage, the mid stage and the late stage of the semester. The online relation networks were respectively reconstructed among the participants according to the interactive behaviours in the forum by Social Network Analysis method. The relation networks among the students in the course forum were high-density networks. The students in these networks got in touch with most active participants and information could be shared among most participants. The important indicators such as "density", "mean distance" and "reciprocity" in the three periods of the semester were calculated. The results showed that the characteristics of the relation networks generated in the three periods differed. Finally, some suggestions were propsed for teacher, limitations and further research plans were proposed.
\end{abstract}

Index Terms-Forum communication, computer-mediated communication, learning analytics.

\section{INTRODUCTION}

In the online learning environments teachers usually focus on every student's behavior and final product while the interactive behaviours among students in the course are often ignored. Taking into account the communications and relationships between students could be helpful to teachers. With the development of computer technology, the data which can represent the online communications between students can be collected. Researchers can apply the learning analytic technology to analyze the collected data. The study focused on the communications among students. Studying the student-student communications can be useful for students to manage their work. Moreover, the analyzing results can be useful for teachers to help the students complete their work better. In this paper we present the study on the interactive online communications among the students in the Cloud Classroom course forum during an 18-week course. The remainder of this paper is organized as follows.

Manuscript received November 12, 2017; revised January 2, 2018. This research was financially supported by the National Science \& Technology Pillar Program (No. 2015BAK33B02), self-determined research funds of CCNU from the colleges' basic research and operation of MOE (No. 230/20205170497), the Informational application of independent scientific research projects in CCNU (No. CCNU16IT0307) and the MOE (Ministry of Education in China) Project of Humanities and Social Sciences (Project No.17YJC880081).

The authors are with the School of Educational Information Technology of Central China Normal University, China (e-mail: 116350703@qq.com, xiadanchina@163.com).
In Sec. II, background literatures are reviewed. In Sec. III, the proposed method is presented in detail. The results are shown in Sec. IV. Finally, this paper ends with the conclusion and future work.

\section{BACKGROUND LITERATURE}

With the development of the online learning environment teachers prefer to construct online collaborative learning in order to enhance the classroom learning [1], [2]. The Social Network Analysis (SNA) method is widely applied in the education field by researchers to study collaborative relationships between learners [3]. The social network consists of nodes and links. The nodes represent social units in the social network such as individuals. And the links represents relationships between social units. The structure and dynamics of the social network can be analyzed by using SNA method [3]. The structure of the social network can be modeled and visualized in the form of graphs by the SNA method. Moreover, the characteristics of the social network can be described by the parameters of the SNA method. There are five main parameters in the SNA method: cohesion, centrality, role-groups, ranges of influence and brokerage [4]. The individual influence scope and socialized relationships among individuals in the network can be described by "cohesion" [5]. The importance of one individual to other individuals in the network is described by "centrality" [6]-[8]. The individuals in the social network consist of core members and peripheral members [9]. The centrality degrees of the core members are high while the centrality degrees of the peripheral members are low. Core members are often more active and more influential than the peripheral members. Hence the core members are more efficient for spreading information. Scholars constructed a three-dimensional analytical model to study the structural characteristics of cooperative networks [6]. Scholars also used SNA method to analyze the individuals' interactive behaviours and discuss the causes of some phenomenon [10]. Researches reveal that understanding of collaborative relationships and information flow should be deepened to strengthen deep communications of individuals in the social network.

\section{RESEARCH METHODS}

\section{A. Participants and Procedure}

This study collected the data from the online Cloud Classroom course forum. Then a network of students' communications in the forums was constructed. The interactive communication network, involving 30 students, 
evolved over one semester. The semester consisted of 18 semester-weeks. The course, entitled Object-Oriented Programming, was delivered in mixed mode which contained online mode and face-to-face mode. In each semester-week students were expected to attend one $1.5 \mathrm{~h}$ lecture and one 1.5 online learning classroom. The course was maintained by cloud platform which was a web-based tool for course management and was used by the University for delivering courses through online mode. The online course forum was shown in Fig. 1. The course forum on the Cloud Classroom Platform was divided into four levels. The four levels were blocks, threads, posts and comments.

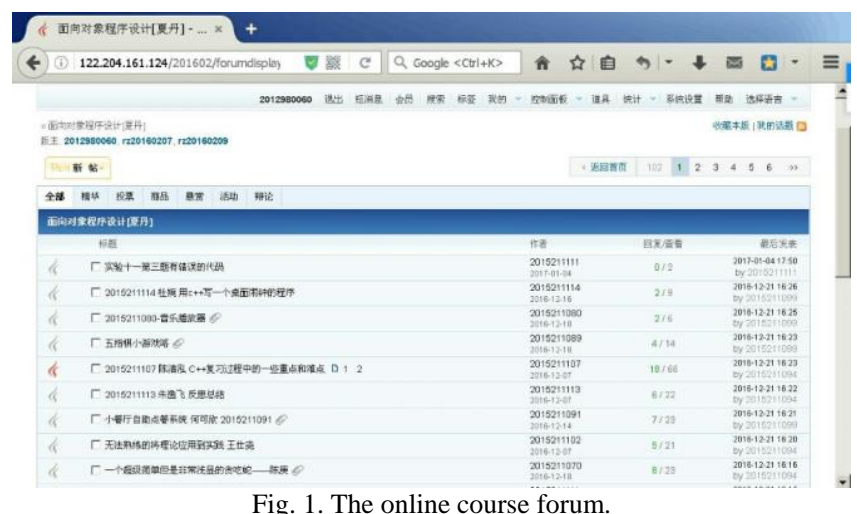

The discussions on the forum were divided into several blocks according to the contents of the discussions. Each block represented a particular theme. The blocks on the Cloud Classroom Platform forums were general discussion block, course discussion block, assignment discussion block, et al. When the students wanted to initiate a new discussion topic he could create a thread corresponding to the topic. In the thread, students could discuss with each other about the topic by posting and commenting on posts. For this research, the online interactive networks were respectively reconstructed from the whole semester which was divided into three six-week periods. The three periods represented the earlier stage, the mid stage and the late stage of the semester.

The participants in the Cloud Classroom course forum included students who learned the course "Object-Oriented Programming". A relation network was constructed among the participants according to the interactive behaviours in the forum. The nodes of network represented the participants while the edges of the network represented the relationships between the participants. The relationship represented the communication between the participants about one topic. A relation network could be constructed by the rule demonstrated above. In order to improve the network density only participants who participated in the activities in the forum more than one time were selected for the research.

\section{B. Quantitative Data Collection and Analysis}

For the research, Social Network Analysis technology was used to study the interactive behaviours among the students in the Cloud Classroom course forum. In order to analyze the cooperative relationships between learners, the comments of the learners in the online forum are collected and sorted out for analysis in SNA. The UCINET software, an analytical technology for SNA, was chosen to study learners' cooperative relationships. Two key parameters were chosen to describe the characteristics of the learners' relationships: cohesion and centrality. Three indicators such as "density", "mean distance" and "reciprocity" were calculated according to the data. The density means the degree of connections among individuals in a network. Distance represents the efficiency of information spreading. Reciprocity reflects the tendency of individuals to reciprocate. Centrality means an individual' influence on other individuals in the network. In the directed network, the in-degree centrality represents the number of connections coming in while the out-degree centrality represents the number of connections coming out [11]. The core individual communicates with other individuals frequently. The core individual often is at the center of the social network. The density of a social network can be obtained by calculating the ratio of the amount of existing edges to the amount of all potential edges in the social network [12]. The distance of a social network can be obtained by calculating the average number of connections in the shortest path connected between two individuals[13]. The in-degree and out-degree centrality values can be obtained by the calculating method described in [14], [15].

\section{RESUlTs}

The distribution of different kinds of discussions in the three periods of the semester is showed in Table I.

TABLE I: DISTRIBUTION OF DIFFERENT KINDS OF DISCUSSIONS IN THE THREE PERIODS

Percentage of discussions in different kinds

\begin{tabular}{lllll}
\cline { 2 - 4 } Period ID & $\begin{array}{l}\text { General } \\
\text { discussion }\end{array}$ & $\begin{array}{l}\text { Course } \\
\text { discussion }\end{array}$ & $\begin{array}{l}\text { Assignment } \\
\text { discussion }\end{array}$ & \\
\hline Period 1 & $27 \%$ & $56 \%$ & $17 \%$ & $100 \%$ \\
Period 2 & $36 \%$ & $31 \%$ & $33 \%$ & $100 \%$ \\
Period 3 & $38 \%$ & $15 \%$ & $47 \%$ & $100 \%$ \\
\hline \hline
\end{tabular}

The statistic data in Table I showed that the amount of posts and comments about "General discussion" and "Assignment discussion" increased throughout three periods. Meanwhile, the amount of posts and comments about "Course discussion" decrease considerably.

According to the data collected from the communications among students in the Cloud Classroom course forum, a social relationship network for each period could be generated. In every network, nodes indicated the individual students while edges meant the relationships among the students.

By analyzing the structure and features of the network we could find students were closely linked with each other in the first period. But in the following period the network became loose. Even some students had no connection to others in the second period which meant they didn't communicate with others in the forum. But in the third period the situation was improved significantly. The numbers of students who had no collected with the others decreased and the students linked with each other more closely in the last period. 
The distributions of in-degree and out-degree centrality values were suitably normalized and measured according to the method described in [14], [15]. There were some differences between the communication networks in the three periods in terms of in-degree and out-degree values. Both the out-degree and in-degree centrality values of some core students became larger significantly in the third period. The significant change in the last period represented the core students exchanged more information from others.

The communication network among the students in the Cloud Classroom course forum was a high-density network. The students in the high density network got in touch with most active participants and information could be shared among most participants. The three indicators such as "density", "mean distance" and "reciprocity" in the three periods of the semester were calculated according to method described in [12], [13]. The results were showed in Table II.

TABLE II: NETWORK COHESION OF THREE PERIODS OF ONLINE COLLABORATIVE LEARNING ACTIVITIES

\begin{tabular}{llll}
\hline \hline Period ID & Density & Mean Distance & Reciprocity \\
\hline Period 1 & 0.625 & 3.748 & 0.608 \\
Period 2 & 0.442 & 2.568 & 0.422 \\
Period 3 & 0.862 & 1.326 & 0.846 \\
\hline \hline
\end{tabular}

The densities of the communication network in the three periods differed. The density of the network in the second period was the minimum while the density of the network in the last period was the maximum. The mean distance of the network in each latter period was smaller than the mean distance of the network in each previous period which means one student could pass fewer nodes to contact another one in the latter period. The reciprocity of the communication network in the second period was the lowest of all.

\section{DISCUSSION AND CONCLUSION}

The communication networks constructed from the interactions among students in the three periods of a semester were all closely connected. The structure and features of the networks represented the majority of students interacted with the others actively. Undoubtedly, the teacher actively organized the communications in the forum as an instructor in order to get better results in teaching. The course entitled Object-Oriented Programming was an optional course for sophomores who majored in digital media technology. The students were familiar with each other. And they were all interested in the course. In the first period of the semester, they posted and received information with each other. In the second period of the semester, they became a little slack. As a result, the out-degree centrality and in-degree centrality of most students decreased slightly compared to the first period. In the last period, the students began to study hard for the exam. The students communicated with each other frequently about the course study. Moreover, they sought help from the teacher for solving the problems. In the whole semester, the core students were the key roles and interacted with each student. So in the second period, the core students should initiate some questions about the details of the course study and give actively feedback to each student to maintain the enthusiasm of students. The teacher also should monitor the communications in the forum regularly and keep the discussion focused. The timely intervention from teacher could improve the teaching effect.

This study investigated the interactive behaviours among students in an online course forum. The results of analysis showed the communication network constructed in the three periods of the semester were closely linked. In different periods, the network presented a bit different characteristics. Some limitations existed in this study. This study did not consider the face-to-face communications among students which may affect their online communications. In the future, we will take into account the non-online communications in order to make results more representative.

\section{ACKNOWLEDGMENT}

We would like to thank the students who learned the course "Object-Oriented Programming" for their active participation in the learning and communication activities in the online course forum in this research.

\section{REFERENCES}

[1] E. Cohen-Sayag and D. Fischl, "Reflective writing in pre-service teachers' Teaching: What does it promote?" Australian Journal of Teacher Education, vol. 37, no. 10, pp. 20-36, October 2012.

[2] N. M. Rigelman, B. Ruben, "Creating foundations for collaboration in schools: Utilizing professional learning communities to support teacher candidate learning and visions of teaching," Teaching and Teacher Education, vol. 28, no. 7, pp. 979-989, October 2012.

[3] K. Stepanyan, R. Mather, and R. Dalrymple, "Culture, role and group work: A social network analysis perspective on an online collaborative course," British Journal of Educational Technology, vol. 45, no. 4, pp. 676-693, July 2014.

[4] X. M. Yang, J. H. Li, X. S. Guo, and X. J. Li, "Group interactive network and behavioral patterns in online English-to-Chinese cooperative translation activity," The Internet and Higher Education, vol. 25, pp. 28-36, April 2015.

[5] C. Haythornthwaite, "Social network analysis: An approach and technique for the study of information exchange," Library \& Information Science Research, vol. 18, no. 4, pp. 323-342, September 1996.

[6] X. F. Lin, X. Y. Hu, Q. T. Hu, and Z. C. Liu, "A Social network analysis of teaching and research collaboration in a teachers' virtual learning community," British Journal of Educational Technology, vol. 47, no. 2, pp. 302-319, March 2016.

[7] M. Á. H. Pavo and J. C. Rodrigo, "Interaction analysis of a blog/journal of teaching practice," Internet and Higher Education, vol. 27, pp. 32-43, October 2015.

[8] S. P. Borgatti and M. G. Everett, "A graph-theoretic perspective on centrality," Social Networks, vol. 28, no. 4, pp. 466-484, October 2006

[9] S. P. Borgatti and M. G. Everett, "Models of core/periphery structures," Social Networks, vol. 21, no. 4, pp. 375-395, October 2000.

[10] P. Tsiotakis and A. Jimoyiannis, "Critical factors towards analysing teachers' presence in on-line learning communities," Internet and Higher Education, vol. 28, pp. 45-58, January 2016.

[11] S. Zhang, Q. T. Liu, W. L. Chen, Q. Y. Wang, and Z. F. Huang, "Interactive networks and social knowledge construction behavioral patterns in primary school teachers' online collaborative learning activities," Computers \& Education, vol. 104, pp. 1-17, January 2017.

[12] C. Haythornthwaite, "Social network analysis: An approach and technique for the study of information exchange," Library \& Information Science, vol. 18, no. 4, pp. 323-342, September 1996.

[13] G. Han, O. P. McCubbins, and T. H. Paulsen, "Using social network analysis to measure student collaboration in an undergraduate capstone course," NACTA Journal, vol. 60, no. 2, pp. 176-182, January 2016.

[14] S. S. Shapiro and M. B. Wilk, "An analysis of variance test for normality (complete samples)," Biometrika, vol. 52, no. 3/4, pp 591-611, December 1965.

[15] M. P. Fay, M. A. Proschan, "Wilcoxon-Mann-Whitney or t-test? On assumptions for hypothesis tests and multiple interpretations of decision rules," Statistics Surveys, vol. 4, pp. 1-39, April 2010. 


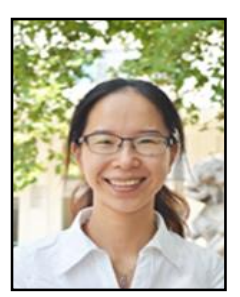

Dan Xia was born in Hubei, China in 1985. She is currently a teacher in School of Educational Information Technology, Central China Normal University, China. Her research interests include: learning analysis, virtual reality, 3D reconstruction.

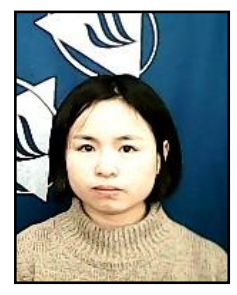

Huirong Ke was born in Anhui, China in 1994. She is currently a master degree candidate in School of Educational Information Technology, Central China Normal University, China, since 2017. Her major is digital media technology. Her research interests include: learning analysis, virtual reality.

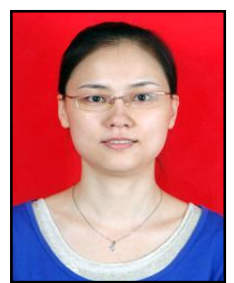

Yuan Tian was born in Hubei, China in 1982. She is currently a teacher in School of Educational Information Technology, Central China Normal University, China. Her research interests include: virtual reality, computer vision, image processing.

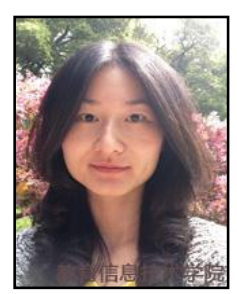

Qiusha Min was born in Hubei, China in 1984. She is currently a teacher in School of Educational Information Technology, Central China Normal University, China. Her research interests include: image processing, 3D reconstruction, distance education, mobile application development.

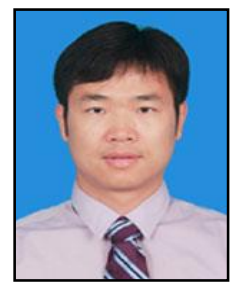

Zhifeng Wang was born in Hubei, China in 1985. He is currently an associated professor in School of Educational Information Technology, Central China Normal University, China. His research interests include: artificial intelligence, image and audio-video intelligent information processing, machine learning, human-computer interaction, game technology, data mining, multimedia forensics. 